\title{
PENGARUH UNSUR-UNSUR IKLAN PAJAK: HIBURAN, INFORMATIF DAN NILAI IKLAN
}

\author{
Michael Christian \\ Manajemen, Universitas Bunda Mulia \\ Alamat surel: michaelchristianid@gmail.com
}

\begin{abstract}
Data from the Director General of Taxes of the Ministry of Finance shows that the level of compliance of the Indonesian people in paying taxes is still relatively low by seeing in 2016 the tax revenue has not reached 100\%. The effectiveness of advertising will be formed when slogan succeeds in bringing people's knowledge, attitudes, and views about a product which is expected to establish brand awareness of the importance of tax benefits for the community. The inadequacy of government targets in tax revenues still requires more targeted strategies in shaping the tax liability for Indonesians. Effectiveness through intense advertising done by the government in fact still needs to be proven. Using SPSS with 60 respodent, this study aims to measure the influence of entertainment factors, informativeness and advertising value to taxpayer. The results of this study explain that the factor of entertainment and advertising value on the advertising tax does not affect taxpayer, while the informativeness factor affects taxpayer. Simultaneously, all independent variables influence the bound variables. Limitations in this study are the use of non-specific taxes and also the use of the number of samples that can still be added

Keywords: tax, entertainment, informativeness, value, compliance
\end{abstract}

\begin{abstract}
Abstrak
Data dari Direktur Jenderal Pajak Kementrian Keuangan menunjukkan bahwa tingkat kepatuhan masyarakat Indonesia dalam membayar pajak masih relatif rendah melihat pada tahun 2016 penerimaan pajak belum mencapai $100 \%$. Efektivitas iklan akan terbentuk ketika slogan iklan berhasil menggiring pengetahuan masyarakat, sikap, dan pandangan mengenai suatu produk yang diharapkan dapat membentuk kesadaran merek akan pentingnya manfaat pajak bagi masyarakat. Ketidaktercapaian target pemerintah dalam angka penerimaan pajak masih memerlukan strategi-strategi yang lebih tepat sasaran dalam membentuk kesadasaran akan pajak bagi masyarakat Indonesia. Efektivitas melalui iklan yang gencar dilakukan oleh pemerintah nyatanya masih perlu dibuktikan lagi. Penelitian ini bertujuan untuk mengukur pengaruh faktor-faktor entertainment, informativeness dan advertising value terhadap kepatuhan wajib pajak (WP). Dengan menggunakan SPSS dan jumlah sampel 60, hasil penelitian ini menjelaskan bahwa faktor entertainment dan advertising value pada iklan pajak tidak mempengaruhi kepatuhan WP, sedangkan faktor informativeness mempengaruhi WP. Secara simultan, semua peubah bebas mempengaruhi peubah terikat. Keterbatasan dalam penelitian ini adalah penggunaan pajak yang tidak spesifik dan juga penggunaan jumlah sampel yang masih dapat ditambah.
\end{abstract}

Kata kunci: pajak, hiburan, informatif, nilai, kepatuhan

\section{PENDAHULUAN}

\section{Latar Belakang}

Slogan-slogan pajak seperti "Orang Bijak Taat Pajak", "Lunasi Pajaknya Awasi Penggunaannya", "Pajak Menyatukan Hati Membangun Negeri", sampai kepada "Bangga Bayar Pajak" rasanya dapat ditemukan di berbagai media baik cetak maupun non cetak. Slogan-slogan tersebut menempel pada pada satu kesatuan atau rangkaian iklan yang disampaikan oleh Direktorat Jenderal Pajak yang sasarannya adalah untuk menciptakan dan meningkatkan kesadaran masyarakat untuk patuh akan pajak. Efektivitas slogan akan terbentuk ketika slogan tersebut berhasil menggiring pengetahuan masyarakat, sikap, dan pandangan mengenai suatu produk yang bila melihat dari konteks pajak aspek-aspek tersebut diharapkan dapat membentuk kesadaran merek akan pentingnya manfaat pajak bagi masyarakat (Hasan, 2013). Penggunan iklan dalam menciptakan dan meningkatkan kesadaran masyarakat dalam membayar pajak dilakukan di hampir semua 
negara, salah satunya Italia yang menggunakan jasa perusahaan Saatchi \& Saatchi untuk membuat iklan yang bertujuan untuk mengurangi masyarakat yang mennghindar dari pajak (Duff, 2011).

Menurut Direktur Jenderal Pajak Kementrian Keuangan, Ken Dwijugiasteadi, tingkat kepatuhan masyarakat Indonesia dalam membayar pajak masih relatif rendah melihat pada tahun 2016 penerimaan pajak berada pada angka $81,54 \%$ dari total target penerimaan sebesar 1,35 triliun rupiah (Tim Viva, 2017). Lebih lanjut dijelaskan bahwa faktor utama penyebab kurangnya kesadaran masyarakat dalam membayar pajak adalah adanya pengaruh dari orang lain. Hal ini menjelaskan bahwa masih mudahnya masyarakat Indonesia terpengaruh oleh orang lain yang tidak memenuhi kewajibannya sebagai wajib pajak (WP). Padahal bila melihat negara tetangga Singapura dan Malaysia, tax ratio masyarakat di dua negara tersebut berada di atas Indonesia yang memiliki angka kurang dari 12\% (Afrianto , 2016).

Ketidaktercapaian target pemerintah dalam angka penerimaan pajak masih memerlukan strategi-strategi yang lebih tepat sasaran dalam membentuk kesadaran akan pajak bagi masyarakat Indonesia. Efektivitas melalui iklan yang gencar dilakukan oleh pemerintah nyatanya masih perlu dibuktikan lagi. Dampak iklan pajak kepada masyarakat sepertinya masih memberikan sinyal kurang efektif secara masif. Namun demikian, tahun 2013 Direktorat Jenderal Pajak (DJP) berhasil menjadi Most Trustee Public Institution kategori Kementrian oleh Lembaga Independen MarkPlus Insight (Kristiani, 2013). Indikator yang digunakan dalam penghargaan tersebut adalah kesadaran masyarakat akan merek, pengetahuan masyarakat akan merek, citra merek, preferensi akan merek, dan loyalitas pada merek. Rendahnya tingkat kesadaran masyarakat dalam membayar pajak sepertinya hanya masalah tingkat besaran angka saja, bila dibandingkan dengan hasil penghargaan tersebut yang mengindikasikan efektivitas kesadaran merek dan unsur lain yang berkaitan dengan pajak.
Penelitian-penelitian terdahulu pernah menjelaskan keterkaitan iklan dalam terhadap kesadaran masyarakat untuk patuh dalam membayar pajak. Iklan menjadi faktor yang memiliki pengaruh terhadap kepatuhan masyarakat dalam membayar pajak (Faizin, Kertahadi, \& Ruhana, 2016; Trisnawati \& Putri, 2014). Namun beberapa penelitian membuktikan bahwa iklan tidak memiliki pengaruh terhadap kepatuhan masyarakat dalam membayar pajak (Tahar \& Rachman, 2014; Waluyo, 2014). Faktor khusus seperti unsur hiburan pada iklan ternyata dibutuhkan dalam suatu iklan (Hatzithomas, Zotos, \& Boutsouki, 2011; Ha , Park, \& Lee, 2014). Suatu iklan juga harus bersifat informatif dan memiliki advertising value(Ha , Park, \& Lee, 2014). Unsur-unsur ditemukan di hampir kebanyakan iklan komersial dan dirasa perlu diuji pada iklan berbentuk layanan masyarakat seperti iklan pajak. Faktor-faktor tersebut perlu diteliti dalam menjelaskan keterkaitan iklan dalam memengaruhi kepatuhan masyarakat dalam membayar pajak. Oleh karena itu, penelitian ini ditujukan untuk meneliti faktor-faktor dalam iklan dalam keterkaitannya terhadap kepatuhan WP.

\section{Masalah Penelitian}

Masalah-masalah yang terdapat dalam penelitian ini adalah sebagai berikut:

1. Apakah kepatuhan WP dipengaruhi oleh faktor hiburan dalam iklan pajak?

2. Apakah kepatuhan WP dipengaruhi oleh faktor informatif dalam iklan pajak?

3. Apakah kepatuhan WP dipengaruhi oleh faktor advertising value dalam iklan pajak?

4. Apakah kepatuhan WP dipengaruhi secara bersama-sama oleh faktor hiburan, informatif, dan advertising value dalam iklan pajak? 


\section{Tujuan Penelitian}

Berdasarkan masalah penelitian yang disebutkan di atas, maka tujuan yang terdapat dalam penelitian ini adalah sebagai berikut:

1. Untuk menjelaskan apakah kepatuhan WP dipengaruhi oleh faktor hiburan dalam iklan pajak?

2. Untuk menjelaskan apakah kepatuhan WP dipengaruhi oleh faktor informatif dalam iklan pajak?

3. Untuk menjelaskan apakah kepatuhan WP dipengaruhi oleh faktor advertising value dalam iklan pajak?

4. Untuk menjelaskan apakah kepatuhan WP dipengaruhi secara bersama-sama oleh faktor hiburan, informatif, dan advertising value dalam iklan pajak?

\section{TINJAUAN PUSTAKA}

\section{Keterkaitan Iklan dan Kepatuhan Membayar Pajak}

Kepatuhan WP dapat diartikan sebagai suatu kondisi dimana WP memiliki sifat patuh dan sadar dalam menjalankan kewajibannya sebagai WP (Rustiyahningsih, 2011). Lebih lanjut dijelaskan bahwa beberapa karakteristik yang dapat tercermin dari tindakan patuh bagi tiap WP adalah sebagai berikut:

1. WP dapat memahami dan memiliki upaya untuk memahami mengenai tata aturan perundang-undangan perpajakan

2. WP melakukan tindakan dengan mengisi formulir pajak secara lengkap dan jelas

3. WP melakukan perhitungan pajak dengan benar

4. WP melakukan pembayaran pajak secara tapat waktu

Berdasarkan paparan di atas dapat dijelaskan bahwa kepatuhan WP tidak hanya mengacu pada kepatuhan dalam ketepatan waktu dalam membayar pajak namun juga berhubungan dengan kepatuhan dalam melakukan pembayaran dengan perhitungan yang benar. Salah perhitungan dapat diminimalisir melalui pesan atau himbauan tata cara menghitung pajak yang dapat disampaikan melalui media iklan.

Iklan sendiri dapat diartikan sebagai satu bentuk cara untuk memperkenalkan barang dan/atau jasa non-personal yang teridentifikasi (Moriarty, Mitchell, \& Wells, 2009). Morrisan (2010) menjelaskan bahwa iklan membutuhkan media untuk menjelaskan pesan kepada masyarakat. Dalam hal penyajian ide dan bentuk promosi dalam iklan diperlukan pembayaran (Ibrahim, 2007). Dalam kaitannya dengan iklan, pajak merupakan suatu bentuk kontribusi wajib kepada negara dari orang pribadi atau badan berdasarkan undangundang yang digunakan untuk keperluan negara bagi sebesar-besarnya kemakmuran rakyat (http://www.pajak.go.id, 2012). Hal ini menjelaskan bahwa media iklan yang digunakan untuk memberikan informasi mengenai pajak dan hal-hal yang terkait di dalamnya dapat dilakukan baik dengan media cetak (surat kabar, majalah) ataupun bentuk media lainnya seperti televisi, radio sampai kepada yang berbentuk daring.

Waluyo (2014) dalam penelitiannya yang menggunakan analisis regresi berganda membuktikan bahwa faktor iklan tidak memberikan pengaruh yang signifikan terhadap kepatuhan wajib pajak dalam membayar pajak bumi dan bangunan (PBB). Terdapat indikasi bahwa hasil ini disebabkan oleh WP belum mengetahui dan memahami makna dan pesan yang disampaikan oleh Otoritas Pajak walaupun iklan disampaikan dengan menggunakan media cetak maupun media elektronik. Hal yang berbeda dibuktikan oleh Trisnawati \& Putri (2014). Penelitian ini menjelaskan bahwa iklan yang dilakukan oleh pemerintah yang bertujuan untuk menjaring masyarakat dalam membayar pajak memiliki pengaruh terhadap tingkat kepatuhan WP. Faizin, Kertahadi, \& Ruhana (2016) berdasarkan penelitiannya menjelaskan hasil yang tidak berbeda dimana iklan sebagai bentuk sosialisasi dalam penelitian ini menjelaskan keterpengaruhannya terhadap kepatuhan masyasrakat sebagai WP dalam membayar pajak. 


\section{Operasionalisasi Konstruk}

berikut:

Bentuk konstruk operasional yang digunakan dalam penelitian ini adalah sebagai

Tabel 1. Operasional Konstruk

\begin{tabular}{lll}
\hline Dimensi & Indikator & Skala Ukur \\
\hline Kepatuhan & 1. Pembayaran tepat waktu & Likert 1-5 \\
& 2. Pembayaran tepat angka (sesuai perhitungan) & \\
\hline 3ntertainment & 3. Denda sebagai sanksi keterlambatan bayar & Likert 1-5 \\
& $\begin{array}{l}\text { 2. Informasi ketentuan pembayaran } \\
\text { 3. Sistem informasi pembayaran yang digunakan }\end{array}$ & \\
\hline Informativeness & 1. Memberikan informasi yang jelas & Likert 1-5 \\
& 2. Iklan ditayangkan tepat waktu & \\
& 3. Iklan merupakan media yang tepat untuk penyampaian & \\
& informasi mengenai pajak & \\
& 4. Iklan menjadi media pelengkap dalam penyampaian & \\
& informasi pajak & \\
\hline Advertising & 1. Informasi pajak di iklan sama dengan yang disampaikan & Likert 1-5 \\
Value & 2. Iklan metugas pajak & \\
& 2. Plangenai pajak perlu untuk diketahui &
\end{tabular}

Sumber: Supriyadi \& Putriana (2010) ; Soediono (2012)

\section{Hipotesis dan Model Penelitian}

Hipotesis dan model yang digunakan dalam penelitian ini adalah sebagai berikut:

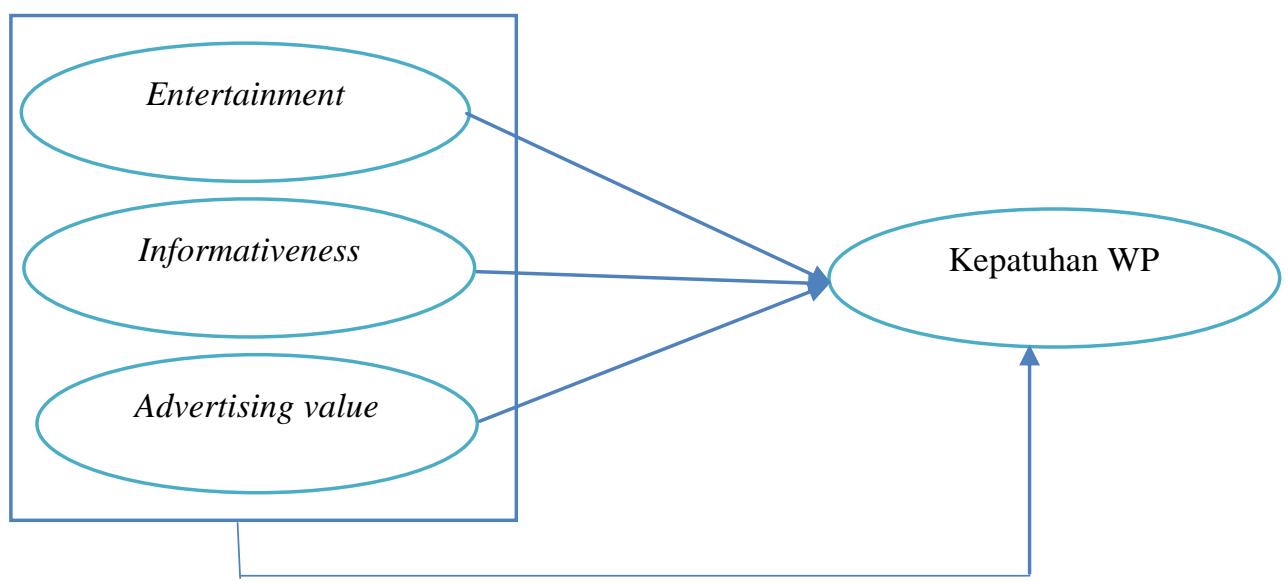

Sumber: Supriyadi \& Putriana (2010) ; Soediono (2012)

Gambar 1. Model Penelitian

H1: Terdapat pengaruh faktor entertainment pada iklan pajak terhadap kepatuhan wajib pajak

$\mathrm{H} 2$ : Terdapat pengaruh faktor informativeness pada iklan pajak terhadap kepatuhan wajib pajak

H3: Terdapat pengaruh faktor advertising value pada iklan pajak terhadap kepatuhan wajib pajak
H4: Terdapat pengaruh faktor entertainment, informativeness, dan advertising valuepada iklan pajak secara bersama-sama terhadap kepatuhan wajib pajak 


\section{Metode Penelitian}

Penelitian ini merupakan penelitian kuantitatif dengan menggunakan 60 sampel. Angka tersebut ditentukan dengan mengalikan indikator dengan 5-10 (Hair, Hult, Ringle, \& Sarstedt, 2013). Penelitian menggunakan alat uji Statistical Package for Social Science (SPSS) 22.0 dengan besar angka galat sebesar 5\%. Serangkaian uji yang akan dilakukan yaitu Uji Kesahihan dan Kehandalan Konstruk, Uji Asumsi Klasik, Regresi Berganda, Koefisien Determinasi, Uji dan uji hipotesis.

\section{HASIL DAN PEMBAHASAN}

\section{Profil dan Deskriptif}

Berdasarkan olahan hasil maka dapat dijelaskan bahwa responden dalam penelitian ini terdiri dari responden perempuan sebanyak 13 orang $(21,7 \%)$ dan responden laki-laki sebanyak 47 orang $(78,3 \%)$. Hasil ini menjelaskan bahwa penelitian ini lebih didominasi oleh responden laki-laki. Berdasarkan usia, penelitian ini memiliki karakter respoden dengan latar belakang usia di atas 50 sebanyak 35 orang atau sebesar 58,3\%, responden dengan usia 41-50 tahun sebanyak 13 orang atau sebesar 21,7\%, responden dengan usia 31-40 dan 18-30 tahun masing-masing sebanyak 6 orang atau masing-masing sebesar $10 \%$. Hasil ini menjelaskan bahwa keterwakilan responden dalam penelitian ini didominasi oleh responden dengan latar belakang usia dewasa yaitu responden dengan usia di atas 50 tahun. Karakter ini sangat bermanfaat untuk mengukur masyarakat yang sudah lama menjadi WP dalam keterkaitannya melihat dan membandingkan iklan mengenai pajak.

Tabel 2. Profil Responden $(n=60)$

\begin{tabular}{lll}
\hline Deskripsi & Jumlah & \% \\
\hline Laki-laki & 13 & 21,7 \\
\hline Perempuan & 47 & 78,3 \\
\hline Usia & & \\
$-\quad 18-30$ tahun & 6 & 10 \\
$-\quad 31-40$ tahun & 6 & 10 \\
$-\quad 41-50$ tahun & 13 & 21,7 \\
$-\quad$ Di atas 50 tahun & 35 & 58,3 \\
\hline
\end{tabular}

Sumber: data primer

\section{Uji Kesahian dan Kehandalan}

Penelitian ini dapat dinyatakan sahih apabila nilai $r$ hitung lebih besar dari $r$ tabel $(0,25)$. Berdasarkan hasil pada corrected item-total correlation maka seluruh butir pada penelitian ini berada di atas 0,25 . Butir E1 dan E2 masing-masing memiliki angka 0,505 dan 0,689 atau 0,681 secara total. Butir I1, I2, I3, dan I4 masing-masing memiliki angka 0,556, 0,578, 0,662, dan 0,603 atau 0,857 secara total. Angka pada butir Av1, Av2, Av3 menunjukkan angka 0,448, 0,674, 0,572 dan secara total berada pada angka 0,712. Butir Ke1,Ke2, dan Ke3 menunjukkan angka yang juga berada di atas 0,25 yaitu $0,557,0,488,0,614$ dan secara total berada pada angka 0,685 . Berdasarkan hasil ini dapat dijelaskan bahwa keseluruhan konstruk dalam penelitian menunjukkan kesahihan atau keajegan. Berdasarkan tabel kehandalan, penelitian ini menunjukkan angka yang menjelaskan kehandalan konstruk suatu penelitian. Tabel reliability statistic menunjukkan cronbach alpha pada angka 0,855 untuk 12 butir. Angka ini berada di atas 0,6 yang menjelaskan arti bahwa konstruk dalam penelitian ini dapat digunakan.

\section{Uji Normalitas}

Uji normalitas dapat menjelaskan apakah analisis regresi dalam penelitian layak digunakan atau tidak. Berdasarkan hasil penelitian, dengan menggunakan metode Kolmogorov Smirnov, angka pada Asymp. Sig menunjukkan angka 0,200 atau berada di atas 0,05. Angka ini menjelaskan bahwa penelitian ini memiliki data yang berdistribusi normal. 
Tabel 3. One-Sample Kolmogorov-Smirnov Test (n=60)

\begin{tabular}{lll}
\hline $\mathrm{N}$ & & Unstandardized Residual \\
\hline Normal Parametersa,b & Mean & 60 \\
\cline { 2 - 3 } & Std. Deviation &, 0000000 \\
\hline \multirow{2}{*}{ Most Extreme DifferencesAbsolute } &, 097 \\
\cline { 2 - 3 } \cline { 2 - 3 } & Positive &, 088 \\
\cline { 2 - 3 } & Negative &,- 097 \\
\hline Test Statistic & &, 097 \\
\hline Asymp. Sig. (2-tailed) & & $, 200 \mathrm{c}, \mathrm{d}$ \\
\hline
\end{tabular}

Sumber: data primer

\section{Uji Multikolinieritas}

Terbentuk atau tidaknya suatu gejala multikolinieritas dapat dilihat dari angka Tolerance (Tol) dan Variance Inflation Factor (VIF). Hasil pada penelitian ini menunjukkan angka pada Tol sebesar 0,644 pada Faktor Entertainment, 0,440 pada faktor Informativeness, dan 0,562 pada faktor Advertising Value. Pada bagian VIF, penelitian ini menunjukkan angka lebih kecil dari 10. Faktor Entertainment menujukkan angka 1,553, faktor Informativeness menujukkan angka 2,274, dan faktor Advertising Value menunjukkan angka 1,781. Kedua hasil pada bagian ini menjelaskan bahwa penelitian ini tidak membentuk suatu gejala multikolinieritas.

\section{Uji Heteroskedastisitas}

Suatu pengamatan penelitian memiliki tingkat kesamaan ataupun ketidaksamaan dari variance yang ada. Hal ini dapat menjelaskan apakah variance dari residual tersebut berbentuk homoskedastisitas atau heteroskedastisitas. Angka sig pada peubah yang ada dalam penelitian ini masing-masing menunjukkan angka di atas 0,05. Faktor Entertainment menunjukkan angka 0,938, angka pada Informativeness menunjukkan angka 0,861 dan angka pada Advertising Value menunjukkan angka 0,294. Berdasarkan hasil ini maka dapat dijelaskan bahwa pada penelitian ini tidak terjadi gejala heteroskedastisitas.

\section{Regresi Linier Berganda}

Berdasarkan hasil yang diperoleh bentuk persamaan regresi berganda dari penelitian ini adalah $\mathrm{Y}=4,334+0,286 \mathrm{X} 1+$ $0,347 \mathrm{X} 2+0,024 \mathrm{X} 3+$ e. Hal ini dapat menjelaskan bahwa jika faktor entertainment dan faktor informativeness bernilai 0 maka faktor kepatuhan akan bernilai 4,334. Selanjutnya jika faktor lainnya tetap dan faktor entertainment pada iklan pajak mengalami kenaikan 1 angka maka faktor kepatuhan akan mengalami kenaikan sebesar 0,2861 . Kemudian jika faktor lainnya tetap dan faktor informativeness pada iklan pajak mengalami kenaikan 1 angka maka faktor kepatuhan akan mengalami kenaikan sebesar 0,347 . Selanjutnya jika faktor lainnya tetap dan faktor advertising value pada iklan pajak mengalami kenaikan 1 angka maka faktor kepatuhan akan mengalami kenaikan sebesar 0,024 .

\section{Analisis Korelasi Ganda \& Determinasi}

Berdasarkan tabel model summary, angka R Square menunjukkan angka 0,594. Hal ini menjelaskan bahwa masih terjadi hubungan moderat antara faktor entertainment, informativeness, dan advertising value terhadap kepatuhan WP dalam membayar pajak. Kemudian angka pada Adjusted R square dapat menjelaskan besaran persentase variasi peubah gayut. Berdasarkan tabel hasil penelitian maka dapat dijelaskan bahwa persentase sumbangan pengaruh peubah bebas (entertainment dan informativeness) 
terhadap peubah gayut (kepatuhan) sebesar 31,8\%. Standard Error of the Estimate dapat menjelaskan banyaknya kesalahan model regresi dalam memprediksikan angka pada peubah gayut. Apabila angka pada Standard error of the estimate kurang dari standar deviasi peubah gayut, maka model regresi semakin baik dalam memprediksi nilai peubah gayut. Dalam hasil penelitian ini dapat dijelaskan banyaknya kesalahan dalam memprediksi peubah gayut sebesar 1,334.

Tabel 4. Model Summary $(\mathrm{n}=60)$

\begin{tabular}{|c|c|c|c|c|}
\hline Model & $\mathrm{R}$ & R Square & Adjusted R Square & $\begin{array}{l}\text { Std. Error of the } \\
\text { Estimate }\end{array}$ \\
\hline 1 &, $594^{\mathrm{a}}$ & ,353 & ,318 & 1,34419 \\
\hline
\end{tabular}

a. Predictors: (Constant), AvTotal, ETotal, ITotal

Sumber: data primer

\section{Uji Hipotesis}

Angka sig. pada peubah X1 (faktor entertainment) pada iklan pajak menunjukkan angka 0,113 atau lebih besar dari 0,05. Berdasarkan hasil ini dapat dijelaskan bahwa Kepatuhan WP dalam membayar pajak tidak dipengaruhi oleh faktor entertainment dalam iklan pajak. Angka pada faktor Informativeness yang menunjukkan angka 0,012 (berada di bawah 0,05) menjelaskan bahwa Kepatuhan dipengaruhi oleh faktor informativeness. Kemudian angka pada faktor Advertising value menunjukkan angka sebesar 0,867 atau berada di atas 0,05 dimana dapat menjelaskan bahwa Kepatuhan WP dalam membayar pajak tidak dipengaruhi oleh faktor Advertising Value dari iklan pajak. Angka pada tabel ANOVA dapat menjelaskan ada tidaknya keterkaitan secara simultan antara peubah bebas terhadap peubah gayut. Berdasarkan hasil penelitian ini, angka pada sig menunjukkan angka 0,000 dimana lebih kecil dari 0,005. Hasil ini menunjukkan bahwa secara simultan faktor entertainment, informativeness dan advertising value memengaruhi kepatuhan WP dalam membayar pajak. Hasil ini sesuai dengan penelitian yang dilakukan oleh Trisnawati \& Putri (2014) dan Faizin, Kertahadi, \& Ruhana (2016) dan menolak hasil penelitian yang dilakukan oleh Waluyo, (2014).

\section{Simpulan}

Berdasarkan hasil dan pembahasan di atas, maka penelitian ini dapat disimpulkan sebagai berikut:

1. Kepatuhan WP dalam membayar pajak tidak dipengaruhi oleh faktor hiburan dalam iklan pajak

2. Kepatuhan WP dalam membayar pajak dipengaruhi oleh faktor informatif dalam iklan pajak

3. Kepatuhan WP dalam membayar pajak tidak dipengaruhi oleh faktor nilai iklan (advertising value) dalam iklan pajak

4. Kepatuhan WP dalam membayar pajak dipengaruhi oleh faktor hiburan, informatif, dan nilai iklan secara bersama-sama dalam iklan pajak

\section{Saran}

Berdasarkan simpulan di atas, maka saran pada penelitian ini adalah:

1. Perlu adanya peningkatan pada unsur hiburan dalam iklan pajak. Iklan-iklan pajak selama ini dirasa masih belum menyajikan unsur hiburan yang dapat menarik perhatian masyarakat dalam melihat iklan pajak. Padahal daya tarik dalam suatu iklan dapat membentuk minat masyarakat dalam melihat suatu iklan dan kemudian dapat mendukung terbentuknya pemahaman dan kesadaran akan pajak. Penggunaan animasi dan cerita pada iklan yang menghibur dirasa mampu menjadikan iklan 
pajak lebih menarik untuk dilihat masyarakat.

2. Pada faktor advertising value, penggunaan pemeran iklan dan karakter dari pemeran iklan dalam suatu konten iklan pajak dirasa mampu untuk membentuk dan membangkitkan unsur nilai dari suatu iklan pajak. Profesi-profesi pemeran iklan yang sedang disorot dalam kasus pajak di Indonesia bisa dijadikan pembentuk nilai iklan yang dapat memberikan dampak pada kesadaran dan kepatuhan WP dalam membayar pajak.

\section{DAFTAR PUSTAKA}

Afrianto , D. 2016. September Rabu, http://economy.okezone.com.

Retrieved September Senin, 2017, from http://economy.okezone.com: http://economy.okezone.com/read/2 016/09/21/20/1495183/7-alasanrendahnya-kesadaran-masyarakatbayar-pajak

Duff, M. 2011. Agustus Minggu, http://www.bbc.com. Retrieved September Senin, 2017, from http://www.bbc.com: http://www.bbc.com/indonesia/maja lah/2011/08/110814_italytaxads

Faizin, M. R., Kertahadi, \& Ruhana, I. 2016. Pengaruh Sosialisasi, Pemahaman, dan Kesadaran Prosedur Perpajakan Terhadap Kepatuhan Wajib Pajak. Jurnal Perpajakan (JEJAK), 9(1), 1-9.

Ha , Y. W., Park, M. C., \& Lee, E. 2014. A framework for mobile SNS advertising effectiveness: user perceptions and behaviour perspective. Behaviour and Information Technology, 33(12), 1333-1346.
Hair, J. F., Hult, G. T., Ringle, C., \& Sarstedt, M. 2013. A Primer on Partial Least Squares Structural Equation Modeling (PLS-SE). Sage Publications, Inc.

Hasan. 2013. November Senin, http://www.pajak.go.id. Retrieved September Senin, 2017, from http://www.pajak.go.id: http://www.pajak.go.id/content/artic le/slogan-merakyat-pajak-meningkat

Hatzithomas, L., Zotos, Y., \& Boutsouki, C. 2011. Humor and cultural values in print advertising: a cross-cultural study. International Marketing Review, 28(1), 57-80.

http://www.pajak.go.id. 2012, April Sabtu. Retrieved September Senin, 2017, from http://www.pajak.go.id: http://www.pajak.go.id/content/belaj ar-pajak

Ibrahim, M. N. 2007. Analisis Pengaruh Media Iklan Terhadap Pengambilan Keputusan Membeli Air Minum Dalam Kemasan Merek Aqua Pada Masyarakat Kuota Palembang. Jurnal Manajemen dan Bisnis Sriwijaya, 5, 44-70.

Kristiani, M. 2013. November Rabu, http://www.pajak.go.id. Retrieved September Senin, 2017, from http://www.pajak.go.id:

http://www.pajak.go.id/content/artic le/pajak-dan-branding

Moriarty, Mitchell, \& Wells. 2009. Advetising Priciple and Practice. 8 Ed. Kencana.

Morrisan. 2010. Periklanan Komunikasi Pemasaran Terpadu . Jakarta: Kencana.

Rustiyahningsih. 2011. Faktor-faktor yang Mempengaruhi Kepatuhan Wajib Pajak. Jurnal Akuntansi, 2, 44-45. 
Soediono, W. 2012. Pengaruh Informativeness, Entertainment, Source of Credibility, dan Irritation Terhadap Consumer Attitude Iklan. Jurnal Bisnis dan Akuntansi, 14(4), 120-130.

Supriyadi, E., \& Putriana, L. 2010. Pengaruh Entertainment, Irritation, dan Informativeness Iklan di Website di Kalangan Mahasiswa Fakultas Ekonomi Universitas Pancasila. Journal The Winners, 11(2), 179-187.

Tahar, A., \& Rachman, A. K. 2014. Pengaruh Faktor Internal dan Faktor Eksternal Terhadap Kepatuhan Wajib Pajak. Jurnal Akuntansi dan Investasi, 15(1), 56-67.
Tim Viva. 2017. Februari Senin, http://www.viva.co.id. Retrieved September Senin, 2017, from http://www.viva.co.id: http://www.viva.co.id/berita/bisnis/8 85212-ini-penyebab-masyarakatmalas-bayar-pajak

Trisnawati, E., \& Putri, I. R. 2014. Pengaruh Pelayanan Aparat Pajak, Iklan Pajak, Dan Kesadaran Wajib Pajak Terhadap Kepatuhan Wajib Pajak yang Terdapat di KPP Pratama Jakarta Pademangan Pada Tahun 2011. Jurnal Akuntansi, 14(1), 5980.

Waluyo. 2014. Analisis Pemahaman Wajib Pajak dan Iklan Otoritas Pajak Terhadap Tingkat Kepatuhan Wajib Pajak. Akuntabilitas, VII(3), 177184. 